Archive for

Organic Chemistry

Arkivoc 2019, part i, 293-303

\title{
Total synthesis of Bruguierols: strategies and tactics
}

\author{
Biswajit Panda* \\ Department of Chemistry, City College, 102/1 Raja Rammohan Sarani, Kolkata-700009, India \\ Email: biswajitchem@gmail.com
}

\section{Dedicated to Dr. Debayan Sarkar to celebrate his $37^{\text {th }}$ birthday}

Received 04-23-2019

Accepted 06-16-2019

Published on line $\quad 07-30-2019$

\section{Abstract}

Bruguierols are an unusual class of natural products exhibiting interesting biological activities like antibacterial activity against both Gram-positive and Gram-negative bacteria including mycobacteria and resistant strains. A considerable number of reports have appeared in the literature dealing with the synthesis and biological activity of bruguierols which asks for a comprehensive review on this topic. Here, the joy and challenges of all synthetic strategies to construct these molecules including comparative studies of diversified approaches and, wherever required, the beauty and uniqueness of the respective synthetic strategy are thoroughly being discussed.<smiles>C[C@]12CC[C@H](Cc3cc(O)ccc31)O2</smiles>

Bruguierol $A(\mathbf{1})$<smiles>C[C@]12CC[C@H](Cc3cc(O)c(O)cc31)O2</smiles>

Bruguierol B(2)<smiles>C[C@]12CC[C@H](Cc3cc(O)cc(O)c31)O2</smiles>

Bruguierol C(3)<smiles>CCCc1cc(O)c(OC)c(OC)c1OC</smiles>

Bruguierol D(4)

Keywords: Bruguierols, $\beta-C-$-Glucoside Natural Products, Heterocycles, Natural Products, Total Synthesis 


\section{Table of Contents}

1. Introduction

2. Biological Properties of Bruguierols

3. Literature Syntheses of Bruguierols

3.1. Ramana's synthesis of (-)-bruguierol A (1)

3.2. Rodriguez's synthesis of (+)-bruguierol A (1)

3.3. Wang's synthesis of racemic bruguierol A (1)

3.4. Venkateswaran's synthesis of racemic bruguierol A (1)

3.5. Jennings's synthesis of (+)-bruguierol C (3)

3.6. Kumar's synthesis of (+)-bruguierol A (1) and (+)-bruguierol B (2)

4. Conclusions

5. Acknowledgements

6. References

\section{Introduction}

Natural product synthesis provides an ideal platform to display the power of organic synthesis and represent the scope and limitations of synthetic skills at a given point in time. To conquer the challenges of synthesizing natural products involves the advancement of the new synthetic methods needed to drive towards higher molecular complexity, diversity and effectiveness. ${ }^{1}$ Not only does total synthesis of natural product provide opportunities for the discovery and development of new synthetic techniques and methodology with applications extending far beyond the discipline, it also delivers an alternative source of natural products with promising biological activity. Oftentimes, natural products are present at very low concentrations in the respective natural source so that a considerable amount of the respective organism needs to be harvested and extracted to afford enough material for additional extensive biological analysis and/or medical use. Thus, total synthesis is often essential to provide sufficient amounts material to satisfy the need. Additionally, natural products can offer a structural podium which can be expanded or simplified to achieve improved potency, better selectivity, reduced toxicity, or other appropriate physical and chemical properties. ${ }^{2}$

Nature has served as a source of medicinal products for millennia, and it is still considered as the most prolific source of new drug molecules. Since primeval times, natural products have been used for medical treatment and have been studied mainly from a chemical point of view. Although marine organisms are difficult to access, technological developments have allowed scientists to arrive in the deepest point of the world's oceans and to collect samples from tropical waters. The specific ecological conditions of mangroves require various morphological and physiological adaptations to cope with the problem of anoxia, high salinity, and common tidal inundation. ${ }^{3}$ The biosynthetic potential of the mangroves to produce a distinct array of novel chemical entities is apparent. Thus, the mangrove ecosystem is considered an attractive biodiversity hotspot that is intensively investigated in the hope for discovering new, structurally unique compounds which display significant biological and pharmacological activities. ${ }^{4}$

In the year 2005, Sattler and co-workers reported the isolation and characterization of an unusual family of aromatic $\beta$-C-glucoside natural products from the stem of the Bruguiera gymmorrhiza mangrove tree, which they collected off the southern coast of Xiamen, China. ${ }^{5}$ They have isolated three natural products having a unique 2,3-benzo-fused-8-oxabicyclo[3.2.1] octane ring system and named them bruguierols A-C. 
Bruguierol A (1) contains one phenolic - $\mathrm{OH}$ groups whereas bruguierol B (2) and C (3) contains two phenolic $\mathrm{OH}$ groups arranged in two different positions. Within this class of natural products, as shown in figure 1 , they had revealed that the inclusion of phenolic hydroxyl group ortho to the quaternary centre is required for the antimicrobial activity.

In the following year, Lin et al. reported ${ }^{6}$ the isolation of bruguierol $D(4)$ from the same tree from which bruguierol A-C were isolated. Compound 4 was isolated as a colourless oil. Its molecular formula $\left(\mathrm{C}_{12} \mathrm{H}_{18} \mathrm{O}_{4}\right)$ was determined by HRESI-MS. The structure was elucidated by NMR spectroscopy. The structure of bruguierol D (4) was elucidated as 2,3,4-trimethoxy-5-propylphenol, which is structurally completely different from bruguierols A-C. Although several racemic and some enantioselective syntheses of these novel natural products have been reported, this is the first review on this topic to the best of our knowledge.

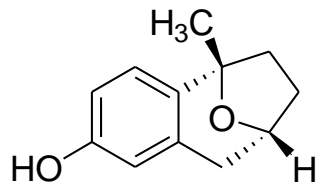

Bruguierol A (1)<smiles>C[C@]12CC[C@H](Cc3cc(O)c(O)cc31)O2</smiles>

Bruguierol B (2)<smiles>C[C@]12CC[C@H](Cc3cc(O)cc(O)c31)O2</smiles>

Bruguierol C (3)<smiles>CCCc1cc(O)c(OC)c(OC)c1OC</smiles>

Bruguierol D (4)

Figure 1. Structure of Bruguierols A-D.

\section{Biological Properties of Bruguierols}

Among the bruguierols A-C, only bruguierol C (3) was shown to exhibit interesting antimicrobial activities against Staphylococcus aureus SG 511, Micrococcus luteus ATCC 10240, Enterococcus faecalis 1528 (VanA), Escherichia coli SG 458, and Mycobacterium vaccae (MT10670) in minimal inhibitory concentration, MIC; 12.5 $\mu \mathrm{g} / \mathrm{ml}$. Two noteworthy observations were made. First, the antimicrobial activity of bruguierol $\mathrm{C}(\mathbf{3})$ against Enterococcus faecalis 1528 is important because of its resistance to other antibiotics such as gentamicin, teicoplanin, and vancomycin A. Second, bruguierol C (3) has the same activity (MIC $12.5 \mu \mathrm{g} / \mathrm{ml}$ ) against Micrococcus luteus ATCC 10240 as ciprofloxacin. It is understood that bruguierol C (3) exhibits activity against both Gram-positive and Gram-negative bacteria. Therefore, it is a potential lead compound for drug discovery for the treatment of bacterial infections.

\section{Literature Syntheses of Bruguierols}

With the interesting structural features and potential biological activities, it is understandable that the features of this family have not gone unnoticed in the synthetic community and several successful syntheses have been developed.

\subsection{Ramana's synthesis of (-)-Bruguierol A (1) $)^{10}$}

Ramana and co-workers have reported a facile method for the construction of benzene-fused 8oxabicyclo[3.2.1.] octane systems by using rhodium catalyzed $(2+2+2)$ cyclotrimerisation reactions of alkenes. They have employed this protocol for the first and expedient total synthesis of (-)-bruguierol A (1) along with the establishment of its absolute configuration. The tricyclic framework was constructed from the alkyne (5) 
and the diyene (6) using Wilkinson's catalyst which provides an inseparable 1:1 mixture of regioisomeric products 7 and 8 in an overall $67 \%$ yield. The mixture was oxidized to the corresponding aldehyde by $\mathrm{MnO}_{2}$ and further elaboration subjected to Baeyer-Villiger oxidation by treatment with m-CPBA provided (-)-bruguierol A (1) and its isomer 9 in a combined yield of 33\%. The excellent agreement of spectroscopic data of synthetic bruguierol A (1) with those of the isolated natural product attests the successful synthesis of this natural product. However, the optical rotation of their synthetic burguierol $A(1)\left\{[\alpha]_{D}=-19.8\left(\mathrm{c}=1.0, \mathrm{CHCl}_{3}\right)\right\}$ was similar to the reported value but opposite in sign, which indicates that the synthetic sample was the enantiomer of bruguierol A (1), defining the absolute stereochemistry of burguierol $A(\mathbf{1})$ as $5 R, 8 S$.

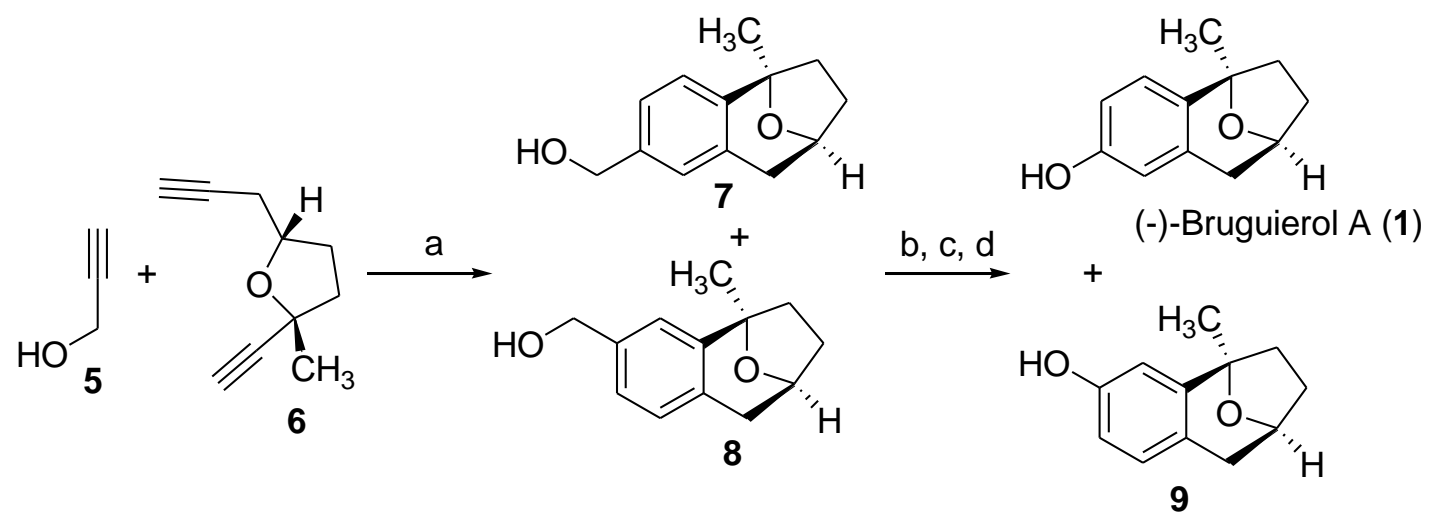

Scheme 1. Synthesis of (-)-Bruguierol A (1). a) Rh(PPh $)_{3} \mathrm{Cl}$, toluene, 85\%; b) $\left.\mathrm{MnO}_{2}, \mathrm{CH}_{2} \mathrm{Cl}_{2} ; \mathrm{c}\right) \mathrm{m}-\mathrm{CPBA} \mathrm{CH}_{2} \mathrm{Cl}$; d) sat. aq. $\mathrm{NaOH}, \mathrm{THF}, 33 \%$ yield over 3 steps.

\subsection{Rodriguez's synthesis of (+)-Bruguierol A (1) $)^{11}$}

Rodriguez and co-workers have reported an elegant approach to the construction of 2,3-benzo-fused-8oxabicyclo[3.2.1]octane derivatives utilizing platinum-catalyzed the sequential hydroalkoxylationhydroarylation reaction of an aryl substituted hex-5-yn-2-ol in an intramolecular tandem fashion.

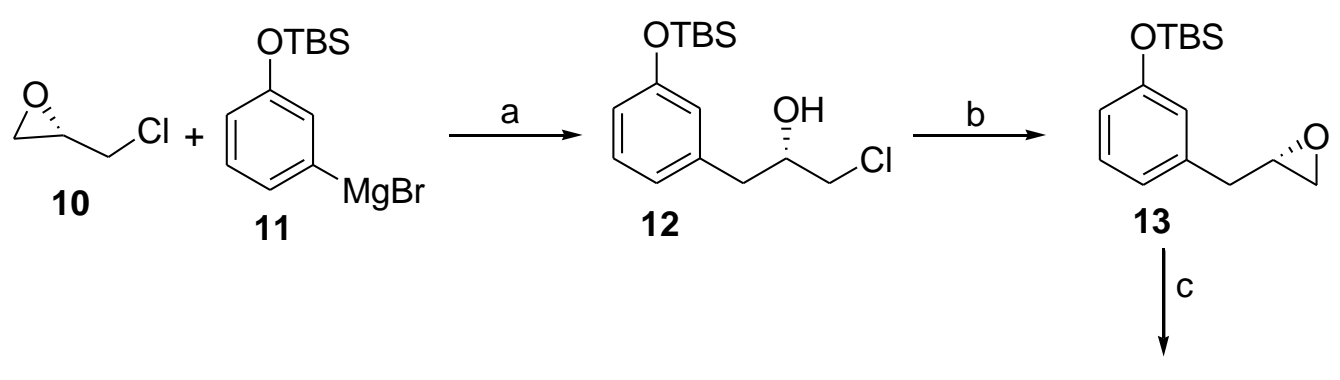

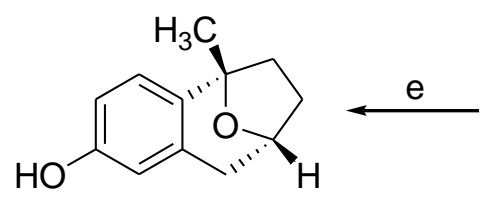

(+)-Bruguierol A (1)

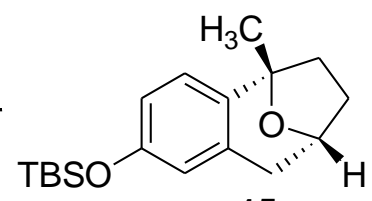

15

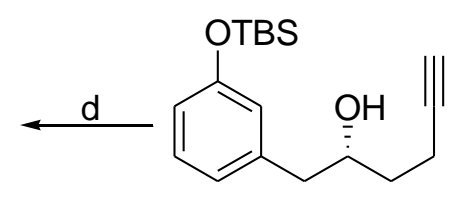

14

Scheme 2. Synthesis of (+)-Bruguierol A (1) a) $\mathrm{Et}_{2} \mathrm{O}, 92 \%$; b) MeLi, THF, 92\%; c) propargylmagnesium bromide, $\mathrm{Et}_{2} \mathrm{O}, 90 \%$; d) 5 mol\% $\mathrm{PtCl}_{4}, \mathrm{CH}_{2} \mathrm{Cl}_{2}, 94 \%$; e) TBAF, THF, 96\%, 69\% overall yield over 5 steps. 
The synthesis of bruguierol A (1) commenced from the commercially available (S)-epichlorohydrin (10) through ring opening of the epoxide by reaction with Grignard reagent 11 to afford the chlorohydrin 12 in excellent yield which reacts further with methyllithium to obtain the new epoxide 13 . Treatment of propargylmagnesium bromide with $\mathbf{1 3}$ afforded the desired pentynol derivative $(R)-\mathbf{1 4}$ as a single regio-isomer with an enantiomeric ratio of $>95: 5$ and $90 \%$ isolated yield. $\mathrm{PtCl}_{4}$-catalyzed intramolecular hydroalkoxylationhydroarylation of pentynol derivatives $(R)-14$ and followed by fluoride-mediated desilylation finally afforded the natural product (+)bruguierol A (1) in a $69 \%$ overall yield.

\subsection{Wang's synthesis of racemic Bruguierol $A(\mathbf{1})^{12}$}

Recently, Wang and co-workers have developed a general and innovative strategy for the formation of bridged oxa- and aza-[n.2.1] skeletons $(n=2,3,4)$ employing a Lewis acid-catalyzed intramolecular [3+2] cycloaddition of cyclopropane 1,1-diesters with aldehydes, ketones, and imines. As a continuation of this work, they have reported the total synthesis of racemic bruguierol $A(1)$ applying $\mathrm{Sc}(\mathrm{OTf})_{3}$-catalyzed intramolecular [3+2] cycloaddition of a cyclopropane. The key cyclopropane substrate $\mathbf{2 0}$ was obtained in four steps from commercially available 3-bromoanisole through Friedel-Crafts acylation, protection of carbonyl group, allylation and, lastly, intramolecular cyclopropanation. The crucial step for congregating the 8oxabicyclo[3.2.1] octane 22 was a Sc(OTf) $)_{3}$-catalyzed tandem intramolecular [3+2]-cycloaddition of 21. Further transformation of $\mathbf{2 3}$ by Krapcho decarboxylation, Barton decarboxylation, and demethylation finally afforded racemic bruguierol $A(1)$ in 10 steps in an overall yield of $6.5 \%$.
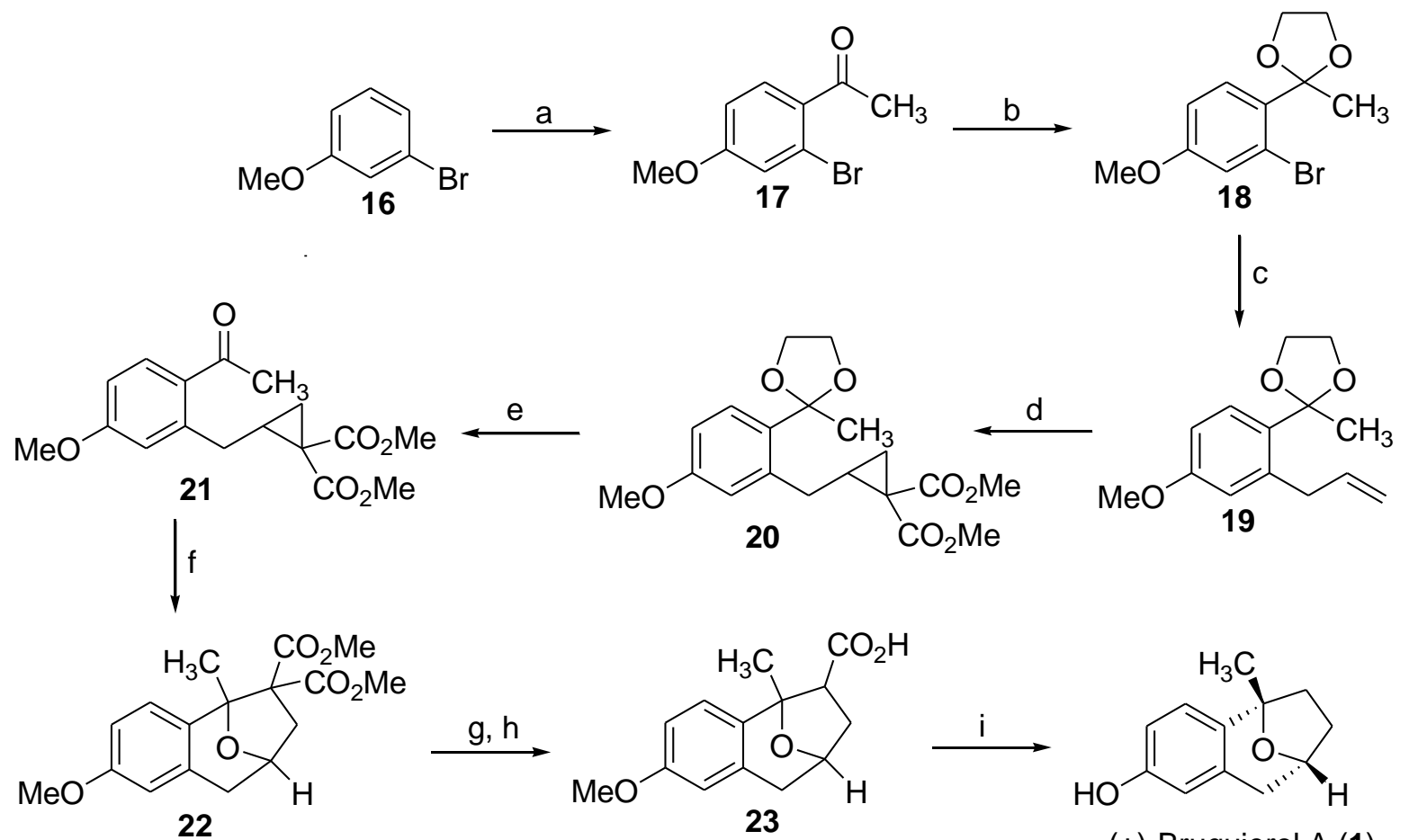

(+)-Bruguierol A (1)

Scheme 3. Synthesis of rac-Bruguierol A (1) a) $\mathrm{AlCl}_{3}, \mathrm{CH}_{3} \mathrm{COCl}, 72 \%$; b) $p$-TsOH, ethylene glycol, $94 \%$; c) $t$-BuLi, $\mathrm{Et}_{2} \mathrm{O}$, allyl bromide, 64\%; d) $\mathrm{N}_{2} \mathrm{C}\left(\mathrm{CO}_{2} \mathrm{Me}\right)_{2}, \mathrm{Rh}_{2}$ (esp) $2,77 \%$; e) $\left.\left.1 \mathrm{M} \mathrm{HCl}, \mathrm{THF}, 95 \% ; f\right) \mathrm{Sc}(\mathrm{OTf})_{3}, \mathrm{DCE}, 98 \% ; \mathrm{g}\right) \mathrm{LiCl}$, wet DMSO, 88\%; h) LiOH, MeOH, $\mathrm{H}_{2} \mathrm{O}, \mathrm{THF}, 88 \%$; i) (1) (COCl) 2 , DMF(cat), $\mathrm{CH}_{2} \mathrm{Cl}_{2}, \mathrm{rt}$, 2h; 2-mercaptopyridine Noxide sodium salt, DMAP(20 mol\%), THF, rt, $2 \mathrm{~h} ; \mathrm{Bu}_{3} \mathrm{SnH}, \mathrm{AIBN}(18 \mathrm{~mol} \%)$, benzene, reflux, 4h, then (2) NaSEt, DMF, 70\% over 2 steps, $6.5 \%$ overall yield over 10 steps. 


\subsection{Venkateswaran's synthesis of racemic Bruguierol A (1) ${ }^{13}$}

Venkateswaran and co-workers reported an elegant and expedient synthesis of bruguierol A (1) employing ring closing metathesis for the construction of the oxa-bridged tricyclic moiety. The synthesis commenced from $m$-hydroxy benzaldehyde and followed by O-protection of the phenol, Wittig homologation of the aldehyde and subsequent Friedel-Crafts acylation afforded the desired keto-aldehyde 27 in good yield. Addition of excess vinyl magnesium bromide furnished diols $\mathbf{2 8}$ as a mixture of isomers. Their separation was not required at this stage as acid-catalyzed cyclization of the mixed diols afforded two cyclic ethers containing two vinyl groups in cis- and trans-arrangement which were easily separable under standard chromatographic conditions. Expectedly, the cis-compound cyclized only in the ring closing metathesis step. ${ }^{14}$ The purification of the cyclized product resulted in a $47 \%$ yield, further hydrogenation in the presence of Wilkinson's catalyst afforded O-ethyl burguierol A (32) in quantitative yield. Finally, sodium ethyl mercaptide mediated deethylation of $\mathbf{3 2}$ furnished the targeted natural product bruguierol A (1) as a crystalline solid. This nice and innovative strategy may also be applicable for the synthesis of bruguierol B (2) and C (3) using the respective phenolic components required.

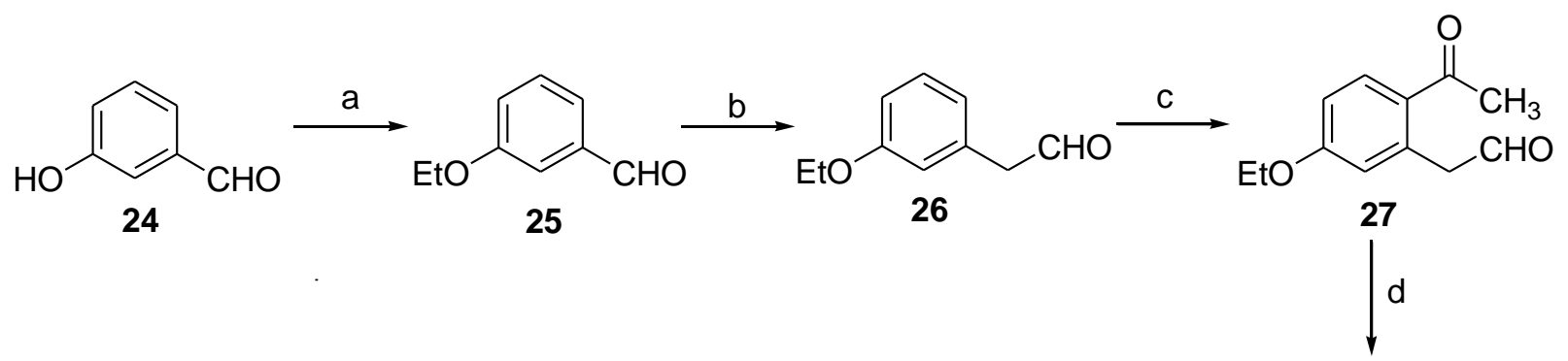

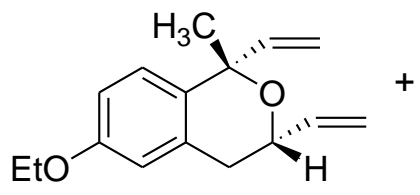

30

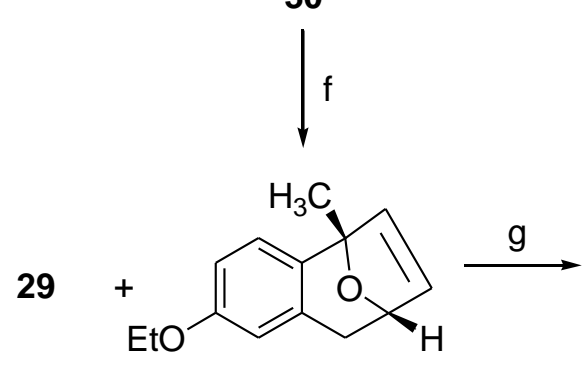

31

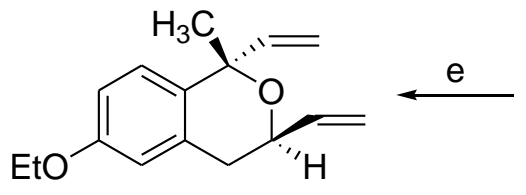

29

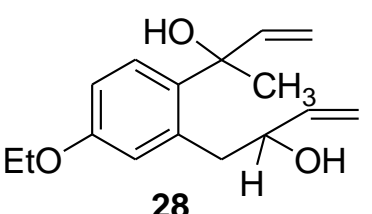

28

Scheme 4. Synthesis of rac-Bruguierol $\mathrm{A}$ (1) (a) $\mathrm{K}_{2} \mathrm{CO}_{3}$, Etl, acetone, reflux, $3 \mathrm{~h}, 90 \%$; (b) potassium tertbutoxide, methoxymethyltriphenyl phosphonium chloride, THF, $5{ }^{\circ} \mathrm{C}$ to rt, $1 \mathrm{~h}$ followed by $2 \mathrm{M} \mathrm{HCl}, \mathrm{THF}, \mathrm{rt}, 4 \mathrm{~h}$, $80 \%$ (for two steps); (c) $\mathrm{CH}_{3} \mathrm{COBr}, \mathrm{AlBr}_{3}, \mathrm{DCM}, 0{ }^{\circ} \mathrm{C}$ to rt, $2 \mathrm{~h}, 60 \%$; (d) vinylmagnesium bromide (2 equiv), THF, $0{ }^{\circ} \mathrm{C}$ to rt, $1 \mathrm{~h}$; (e) $1 \mathrm{M} \mathrm{H}_{2} \mathrm{SO}_{4}$, THF, rt, $30 \mathrm{~min}, 60 \%$ (for two steps); (f) Grubbs' Il catalyst (0.005 mol), DCM, rt, 7 h, 47\%; (g) Rh(PPh $)_{3} \mathrm{Cl}, \mathrm{H}_{2}, \mathrm{EtOH}, \mathrm{rt}, 11 \mathrm{~h}, 98 \%$; (h) EtSNa, DMF, $110{ }^{\circ} \mathrm{C}, 12 \mathrm{~h}, 86 \%, 10.3 \%$ overall yield over 8 steps.

\subsection{Jennings'synthesis of (+)-Bruguierol C (3)}

Jennings and co-workers have described an admirable synthesis of bruguierol $\mathrm{C}$ (3) comprising the diastereoselective trapping of an in situ generated oxocarbenium ion through an intramolecular Friedel-Crafts 
alkylation. Remarkably, the three-step reaction sequence of alkylation, oxocarbenium formation to afford 36 and final intramolecular Friedel-Crafts alkylation provided the expected product $\mathbf{3 7}$ with an overall $58 \%$ yield from lactone 35. Finally, fluoride-mediated desilylation of $\mathbf{3 7}$ afforded the desired targeted natural product bruguierol C (3) in good yield. The excellent agreement of spectral data $\left({ }^{1} \mathrm{H} N M R,{ }^{13} \mathrm{C} N M R\right)$, optical rotation and HRMS data of synthetic (+)-bruguierol C (3) with the authentic natural product attests the success of this strategy and permitted the assignment of the absolute configuration of this natural product.

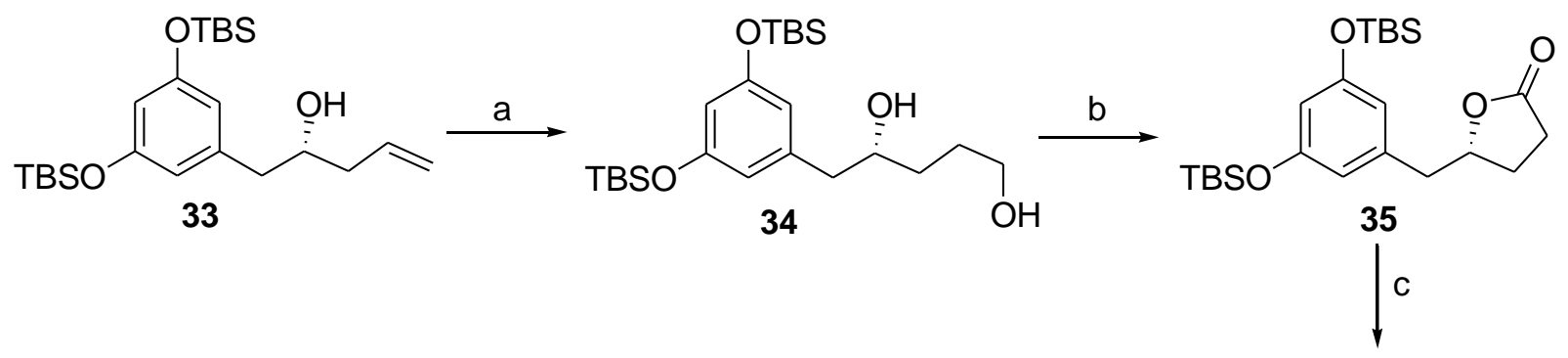

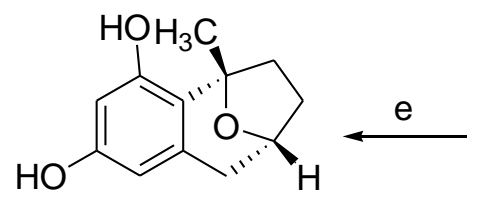

(+)-Bruguierol C (3)

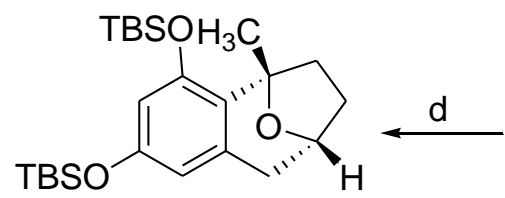

37

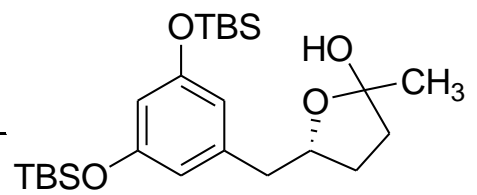

36

Scheme 5. Synthesis of (+)-Bruguierol C (3) (a) $\mathrm{Chx}_{2} \mathrm{BH}, 0{ }^{\circ} \mathrm{C}-\mathrm{rt}, 10 \mathrm{~h}$; $\mathrm{NaOH}, \mathrm{H}_{2} \mathrm{O}_{2}, 0{ }^{\circ} \mathrm{C}-\mathrm{rt}, 4 \mathrm{~h}, 91 \%$; (b) TPAP$\mathrm{NMO}, \mathrm{CH}_{2} \mathrm{Cl}_{2}, \mathrm{rt}, 12 \mathrm{~h}, 68 \%$; (c) MeLi, THF, $-78{ }^{\circ} \mathrm{C}, 1.5 \mathrm{~h}$; (d) $\mathrm{BF}_{3} . \mathrm{OEt}_{2}, \mathrm{CH}_{2} \mathrm{Cl}_{2},-20{ }^{\circ} \mathrm{C}, 2 \mathrm{~h}$, overall two steps $58 \%$ (e) TBAF, THF, rt, $1.5 \mathrm{~h}, 85 \%$.

\subsection{Kumar's synthesis of (+)-Bruguierol A (1) and (+)-Bruguierol B (2) ${ }^{16}$}

Following Jennings's synthetic pathway applied for the synthesis of (+)-bruguierol C (3), Kumar et al. reported the synthesis of $(+)$-bruguierol $A(\mathbf{1})$ and $(+)$-bruguierol B (2). For the synthesis of $(+)$-bruguierol $A(\mathbf{1})$, the synthesis commenced from commercially available 3-hydroxy benzaldehyde $\mathbf{3 3}$ followed by Wittig olefination, O-protection of the phenol and hydrogenation of corresponding olefin $\mathbf{3 5}$ furnished saturated ester $\mathbf{3 6}$ in good yields (Scheme 6). The DIBAL-H-reduction of ester $\mathbf{3 6}$ afforded aldehyde $\mathbf{3 7}$ which was directly subjected to sequential D-proline-catalyzed $\alpha$-aminoxylation followed by HWE-olefination, hydrogenation and cyclization furnished the chiral $\gamma$-butyrolactone $\mathbf{3 9}$ in satisfactory yields. Then, following Jennings' strategy, alkylation, oxocarbenium formation and intramolecular Friedel-Crafts alkylation provided TBS-protected bruguierol A (15). Fluoride-mediated deprotection of TBS-group afforded (+)-bruguierol A (1) in $90 \%$ isolated yield. After successful synthesis of (+)-bruguierol A (1), they focused their attention on (+)-bruguierol B (2). The synthetic pathway for (+)-bruguierol B (2) followed the same strategy as the sythesis of (+)-bruguierol A (1) (Scheme 7). Full agreement was found for spectroscopic data $\left({ }^{1} \mathrm{H} N M R,{ }^{13} \mathrm{C} N M R, I R\right), H R M S$ and optical rotation of synthetic (+)-bruguierol A (1) and (+)-bruguierol B (2) with the respective data of the authentic natural products. 
<smiles>CCOC(=O)CCc1cccc(OCC(C)C)c1</smiles><smiles>CCOC(=O)/C=C/c1cccc(OC(C)(C)C)c1C</smiles><smiles>CC(C)(C)Oc1cccc(C[C@@H]2CCC(=O)O2)c1</smiles><smiles>CC(C)COc1ccc2c(c1)C[C@H]1CC[C@@]2(C)O1</smiles>
15<smiles>CC#CC1CC[C@H]2Cc3cc(O)ccc3[C@]1(C)C2</smiles>

(+)-Bruguierol A (1)

Scheme 6. Synthesis of (+)-Bruguierol A(1) (a) PPh $3=$ CHCOOEt, THF, rt, 24 h, 90\%; (b) TBDMSCl, Imidazole, DCM, 8 h, 95\%; (c) $\mathrm{H}_{2} / \mathrm{Pd}-\mathrm{C}$, EtOAc, 4h, 96\%. (d) DIBAL-H, DCM, -78 ${ }^{\circ} \mathrm{C}, 45 \mathrm{~min}$; (e) (i) Nitrosobenzene, $D-$ proline, DMSO, 30 min, (ii) HWE salt, DBU, LiCl, $\mathrm{CH}_{3} \mathrm{CN}$, 1h; (f) (i) $\mathrm{H}_{2} / \mathrm{Pd}-\mathrm{C}$, EtOAc, $4 \mathrm{~h}$; (ii) Pd/C, EtOAc, $65^{\circ} \mathrm{C}, 6$ h, $60 \%$ over 3 steps. (g) MeLi, Et ${ }_{2} \mathrm{O} 1.5 \mathrm{~h},-78{ }^{\circ} \mathrm{C}, 1.5 \mathrm{~h}$; (h) $\mathrm{BF}_{3} . \mathrm{OEt}_{2}, \mathrm{DCM},-20{ }^{\circ} \mathrm{C}, 2 \mathrm{~h}, 60 \%$ over 2 steps; (i) TBAF, THF, rt, 2 h, $90 \%$.

A comparison among the synthetic approaches can be drawn from the overall yields and number of steps used to achieve the target molecule, bruguierol A (1). Ramana's synthesis of (-)-bruguierol A (1) provides $33 \%$ yield over three steps. Rodriguez's synthesis of (+)-bruguierol A (1) furnishes $69 \%$ overall yield over five steps. On the other hand, Wang's synthesis of racemic bruguierol A (1) gives $6.5 \%$ overall yield over ten steps. Venkateswaran's synthesis of racemic bruguierol A (1) provides $10.3 \%$ overall yield over eight steps. Kumar's synthesis of (+)-bruguierol A (1) furnished $26.6 \%$ overall yields over nine steps. 
<smiles>CCOC(=O)/C=C/c1ccc(O)c(O)c1</smiles>

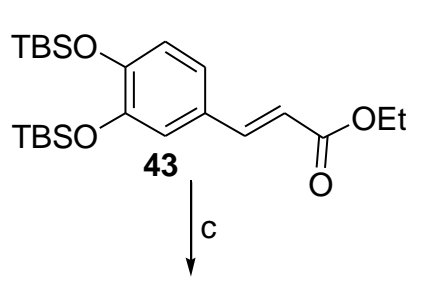<smiles>CCOC(=O)CCc1ccc(OCC)c(OCC(C)(C)C)c1</smiles>

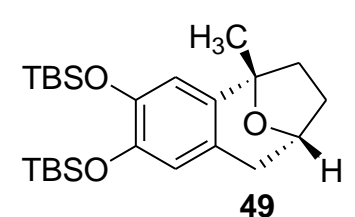<smiles>CC#CC1CC[C@H]2Cc3cc(O)c(O)cc3[C@]12C</smiles>

(+)-Bruguierol B (2)

Scheme 7. Synthesis of (+)-Bruguierol B (2) (a) $\mathrm{PPh}_{3}, \mathrm{BrCH}_{2} \mathrm{COOEt}$, sat. $\mathrm{NaHCO}_{3}, 0{ }^{\circ} \mathrm{C}-\mathrm{rt}, 6 \mathrm{~h}, 80 \%$; (b) TBDMSCl, Imidazole, DCM, $0{ }^{\circ} \mathrm{C}-\mathrm{rt}, 12 \mathrm{~h}, 90 \%$; (c) $\mathrm{H}_{2} / \mathrm{Pd}-\mathrm{C}$, EtOAc, rt, 4 h, 90\%;(d) DIBAL-H, DCM, $-78^{\circ} \mathrm{C}, 45 \mathrm{~min}$; (e) (i) Nitrosobenzene, D-proline, DMSO, 30 min; (ii) HWE salt, DBU, LiCl, $\mathrm{CH}_{3} \mathrm{CN}$; 1 h; (f) (i) $\mathrm{H}_{2} / \mathrm{Pd}-\mathrm{C}$, EtOAc; 3 h; (ii) $\mathrm{Pd} / \mathrm{C}$, EtOAc, $65{ }^{\circ} \mathrm{C}, 10 \mathrm{~h}$, (45\% over 4 steps); (g) MeLi, Et ${ }_{2} \mathrm{O}, 3 \mathrm{~h},-78{ }^{\circ} \mathrm{C}, 1.5 \mathrm{~h}$; (h) BF $\cdot \mathrm{OEt}_{2}, \mathrm{DCM}, 2 \mathrm{~h},-20{ }^{\circ} \mathrm{C}$, $50 \%$; (i) TBAF, THF, rt, 3 h, 90\%.

\section{Conclusions}

Certainly, the biological evaluation, and implementation of various unique methodologies for the construction of bruguierols are found to be an active area of interest among synthetic chemists. The antibiotic activity of bruguierol $\mathrm{C}$ is likely to spark further developments in drug discovery. Thus, bringing progress to the synthesis of bruguierol-type natural products and evolution of further biological activities, as well as the elucidation of their mode of action are current tasks for both organic and biochemists. Moreover, advancements in the synthesis of bruguierols will provide to expediting access of other more complex molecular architectures.

\section{Acknowledgements}

I wish to thank City College, Kolkata-700009 for their generous support to accomplish this work. I am thankful to Prof. Sitangshu Sekhar Bhattacharjee and all the faculty members of the Department of Chemistry, City College, Kolkata, for continuous help and encouragement. I express my sincere thanks and gratitude to Prof. 
Amal Kumar Gooyee for his enormous help. I am also thankful to Dr. Debayan Sarkar, Associate Professor, NIT Rourkela, for support and encouragement.

\section{References}

1. Nicolaou, K. C.; Yue, E. W. Pure \&Appl. Chem. 1997, 69, 413.

https://doi.org/10.1351/pac199769030413

2. Baran, P. S. J. Am. Chem. Soc. 2018, 140, 4751.

https://doi.org/10.1021/jacs.8b02266

3. Thornburg, C. C.; Zabriskie, T. M.; McPhail, K. L. J. Nat. Prod. 2010, 73, 489. https://doi.org/10.1021/np900662k

4. $\quad$ Li, M. Y.; Xiao, Q.; Pan, J. Y.; Wu, J. Nat. Prod. Rep. 2009, 26, 281. https://doi.org/10.1039/B816245J

5. Han, L.; Huang, X.; Sattler, I.; Moellmann, U.; Fu, H.; Lin, W.; Grabley, S. Planta Med. 2005, 71, 160. https://doi.org/10.1055/s-2005-837784

6. Han, L.; Huang, X.-S.; Sattler, I.; Fu, H. Z.; Grabley, S.; Lin, W. H. J. Asian. Nat. Prod. Res. 2007, 9, 327. https://doi.org/10.1080/10286020600727574

7. Onyeji, C. O.; Nicolaou, D. P.; Nightingale, C. H.; Bow, L. Int. J. Antimicrob. Agents 1999, 11, 31. https://doi.org/10.1016/S0924-8579(98)00085-5

8. Lefort, A.; Baptista, M.; Fantin, B.; Depardieu, F.; Arthur, M.; Carbon, C.; Courvalin, P. Antimicrob. Agents Chemother. 1999, 43, 476.

https://doi.org/10.1128/AAC.43.3.476

9. Von Eiff, C.; Peters, G. Eur. J. Clin. Microbiol. Infectious Diseases. 1998, 17, 890. https://doi.org/10.1007/s100960050218

10. Ramana, C. V.; Salian, S. R.; Gonnade, R. G. Eur. J. Org. Chem. 2007, 725483. https://doi.org/10.1002/ejoc.200700648

11. Fañanas, F. J.; Fernandez, A.; Cevic, D.; Rodriguez, F. J. Org. Chem. 2009, 74, 932. https://doi.org/10.1021/j08021204

12. Hu, B.; Xing, S.; Ren, J.; Wang, Z. Tetrahedron 2010, 66, 5671. https://doi.org/10.1016/j.tet.2010.05.057

13. Sarkar, D.; Venkateswaran, R. V. Tetrahedron Lett. 2011, 52, 3232. https://doi.org/10.1016/j.tetlet.2011.04.050

14. Panda, B. Asian J. Org. Chem. 2018, 7, 2386. https://doi.org/10.1002/ajoc.201800515

15. Martinez-Solorio, D.; Jennings, M.P. J. Org. Chem. 2007, 72, 6621. https://doi.org/10.1021/jo071035I

16. Cherian, S. K., Ph.D Thesis, Savitribai Phule Pune University, India, 2013. 


\section{Authors' Biographies}

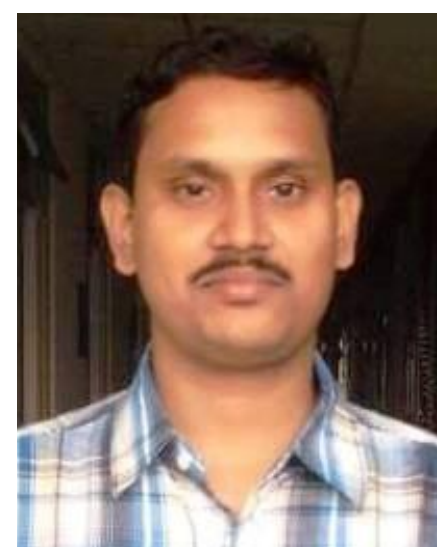

Dr. Biswajit Panda obtained his Ph.D. in chemistry in 2012 under the guidance of Prof. Tarun K. Sarkar at Indian Institute of Technology, Kharagpur (IIT KGP), India. His work involved the synthesis of xyloketal natural products and Pd-Au dual catalytic synthetic methodology developments. In 2013, he joined the laboratory of Prof. Tien Y. Luh at National Taiwan University, Taiwan as a postdoctoral fellow where he worked on the development of new cyclopropene based conducting polymers. In 2015, he returned to India and joined as an Assistant Professor of Chemistry, City College, Kolkata-700009, under the University of Calcutta. At present, the stereoselective synthesis of natural products with potent biological activity and development of new synthetic organic methodologies are the main research interest of Dr. Panda. 